\title{
Stage II Ovarian Cancer AJCC v6 and v7
}

National Cancer Institute

\section{Source}

National Cancer Institute. Stage I/ Ovarian Cancer AJCC v6 and v7. NCI Thesaurus. Code C7830.

Stage II includes: T2, N0, M0. T2: Tumor involves one or both ovaries with pelvic extension and/or implants. N0: No regional lymph node metastasis. M0: No distant metastasis. (AJCC 6th and 7th eds.) 